\section{Kidney \\ Blood Pressure Research}

\title{
Early Markers of Cardiovascular Risk in Autosomal Dominant Polycystic Kidney Disease
}

\author{
Silvia Lai ${ }^{a}$ Daniela Mastroluca ${ }^{b}$ Silvia Matino ${ }^{c}$ Valeria Panebianco ${ }^{d}$ \\ Antonio Vitarellie Lidia Capotosto ${ }^{e} \quad$ Irene Turinese $^{f}$ Paolo Marinellif \\ Marco Rossettif $\quad$ Alessandro Galanig Pia Baiocchif ${ }^{f}$ Anna R. D'Angelo ${ }^{h}$ \\ Paolo Palangef
}

aDepartment of Clinical Medicine, Sapienza University of Rome; ${ }^{b}$ Nephrology and Dialysis Unit, Hospital ICOT Latina, Sapienza University of Rome; ' Nephrology, Dialysis and Trasplantation Unit, University of Bari; dDepartment of Radiological, Oncological and Pathological Sciences, Sapienza University of Rome; 'Department of Cardiovascular, Respiratory, Nephrological and Geriatric Sciences, Sapienza University of Rome; fDepartment of Public Health and Infectious Diseases, Sapienza University of Rome; ${ }^{9}$ Department of Clinical and Experimental Sciences, University of Brescia; ${ }^{\mathrm{h} D e p a r t m e n t}$ of ObstetricalGynecological Sciences and Urologic Sciences, Sapienza University of Rome, Italy

\section{Key Words}

Autosomal dominant polycystic kidney disease $\bullet$ Cardiovascular risk $\bullet$ Inflammation

\begin{abstract}
Background/Aims: Cardiovascular disease is the most frequent cause of morbidity and mortality in autosomal dominant polycystic kidney disease (ADPKD) patients, often before the onset of renal failure, and the pathogenetic mechanism is not yet well elucidated. The aim of the study was to identify early and noninvasive markers of cardiovascular risk in young ADPKD patients, in the early stages of disease. Methods: A total of 26 patients with ADPKD and 24 control group, matched for age and sex, were enrolled, and we have assessed inflammatory indexes, mineral metabolism, metabolic state and markers of atherosclerosis and endothelial dysfunction (carotid intima media thickness (IMT), ankle brachial index $(A B I)$, flow mediated dilation (FMD), renal resistive index (RRI), left ventricular mass index $(\mathrm{LVMI})$ ) and cardiopulmonary exercise testing (CPET), maximal $\mathrm{O}_{2}$ uptake $\left(\mathrm{V}^{\prime} \mathrm{O}_{2}\right.$ max), and $\mathrm{O}_{2}$ uptake at lactic acid threshold $\left(\mathrm{V}^{\prime} \mathrm{O}_{2} @ L \mathrm{LT}\right)$. Results: The ADPKD patients compared to control group, showed a significant higher mean value of LVMI, RRI, homocysteine (Hcy), Homeostasis Model Assessment-insulin resistance (HOMA-IR), serum uric acid (SUA), CardiactroponinT (cTnT) and intact parathyroid hormone (iPTH) ( $p<0.001, p<0.001, p<0.001, p<0.001$, $p<0.001, p=0.007, p=0.019$; respectively), and a lower value of FMD and 25-hydroxyvitamin $D$ $(25-\mathrm{OH}-\mathrm{VitD})(\mathrm{p}<0.001, \mathrm{p}<0.001)$ with reduced parameters of exercise tolerance, as $\mathrm{V}^{\prime} \mathrm{O}_{2}$ max, $\mathrm{V}^{\prime} \mathrm{O}_{2} \mathrm{max} / \mathrm{Kg}$ and $\mathrm{V}^{\prime} \mathrm{O}_{2} \max (\%$ predicted) $(\mathrm{p}<0.001, \mathrm{p}<0.001, \mathrm{p}=0.018$; respectively), and




\section{Kidney Blood Pressure Research}

metabolic response indexes $\left(\mathrm{V}^{\prime} \mathrm{O}_{2} @ L \mathrm{LT}, \mathrm{V}^{\prime} \mathrm{O}_{2} @ \mathrm{LT} \%, \mathrm{~V}^{\prime} \mathrm{O}_{2} @ \mathrm{LT} / \mathrm{Kg},\right)(\mathrm{p}<0.001, \mathrm{p}=0.14, \mathrm{p}<0.001$; respectively). Moreover, inflammatory indexes were significantly higher in ADPKD patients, and we found a positive correlation between HOMA-IR and C-reactive protein (CRP) $(r=0.507$, $p=0.008)$, and a negative correlation between HOMA-IR and 25-OH-VitD $(r=-0.585, p=0.002)$. Conclusion: In our study, ADPKD patients, in the early stages of disease, showed a greater insulin resistance, endothelial dysfunction, inflammation and mineral metabolism disorders, respect to control group. Moreover, these patients presented reduced tolerance to stress, and decreased anaerobic threshold to CPET. Our results indicate a major and early cardiovascular risk in ADPKD patients. Therefore early and noninvasive markers of cardiovascular risk and CPET should be carried out, in ADPKD patients, in the early stages of disease, despite the cost implication.

(C) 2017 The Author(s)

Published by S. Karger AG, Basel

\section{Introduction}

Autosomal dominant polycystic kidney disease (ADPKD) is the most common inherited renal disorder, characterized by progressive fluid-filled cyst development, and growth that lead to end stage renal disease (ESRD) in $50 \%$ of patients, by the age of 50-60 years [1-3]. The estimated prevalence is between 1:400 and 1:1000 live births [4]. About $8-10 \%$ of patients on renal replacement therapy (RRT) are affected by ADPKD [5-7]. Mutations in two genes, PKD1 (localized on chromosome region 16p13.3 and encoding polycystin 1 [PC1]; 85\% of cases) and PKD2 (localized on chromosome region 4q21 and encoding polycystyn 2 [PC2]; 15\% of cases) [8-10], cause the disease. Mutations in PC1 and PC2, transmembranes glicoproteins that are colocalized to the primary cilium of the kidney tubular epithelial cells, cause lower intracellular levels of calcium and increased intracellular cyclic adenosine monophosphate, with aberrant cell proliferation and fluid secretion into cysts [11-13]. ADPKD is a systemic disease, that may involve different organs, showing a high phenotypic variability [14-15], and cardiovascular complications are the major cause of morbidity and mortality, with a cardiac-related death that is estimated to be 1.6- to 3.2-fold higher in these patients than in the general population [16-17]. Currently, there are no prognostic tools to identify ADPKD patients with high cardiovascular risk.

\section{Materials and Methods}

The study was approved by the Local Clinical Research Ethics Committee, with protocol number 3169/15. The study conforms to the principles outlined in the Declaration of Helsinki, and we obtained a written consent by each patient enrolled.

Study design and subjects

We performed an observational, cross-sectional study on 50 patients, 26 ADPKD patients and 24 control group matched for age and sex, at the University Hospital "Policlinico Umberto I" of Rome, Sapienza University of Rome, Italy. Patients were enrolled from July 2015 to April 2016.

\section{Patients}

A total of 26 patients affected by ADPKD ( 6 male; 20 female), and 24 control group ( 8 male; 16 female), were matched for age and sex. 21 ADPKD patients and 18 control group patients were hypertensive. The presence of secondary hypertension had previously ruled out. Both groups had good blood pressure control and antihypertensive therapies were continued in all patients included in the study (Table 1). Two patients of ADPKD group were smoker, and one patient of control group was a mildly smoker up to 8 years before. 


\section{Kidney Blood Pressure Research}

Inclusion criteria

Patients aged $>18$ years with ADPKD

ADPKD was defined according to the Pei's criteria [18]. Estimated Glomerular Filtration Rate $(\mathrm{eGFR}) \geq 80 \mathrm{ml} / \mathrm{min}$

The eGFR was calculated with the abbreviated Chronic kidney disease-epidemiology formula (CKD-EPI), as defined by Levey et al [19].

\section{Exclusion criteria}

We recorded the cardiovascular history and excluded patients affected by heart failure, neoplastic diseases, chronic liver disease, chronic obstructive airway disease, congenital heart disease, cerebrovascular disease, carotid artery stenosis, and acute coronary syndrome three months before of the study. We excluded also patients with diabetes, urinary abnormalities, suggestive of concomitant glomerular disease and urinary tract infection. Patients who refused to give consent and patients with missing data.

All patients performed the morpho-functional Magnetic Resonance (MR) without contrast medium, to exclude the presence of cerebral aneurysms, exclusion criterion of this study.

\section{Laboratory measurements}

Blood was sampled the morning after overnight fasting of at least $12 \mathrm{~h}$, for laboratory assessment. In all patients, the levels of fasting plasma glucose $(\mathrm{mg} / \mathrm{dL})$, insulin $(\mu \mathrm{U} / \mathrm{mL})$, total serum cholesterol $(\mathrm{mg} / \mathrm{dL})$, triglycerides (mg/dL), high-density lipoprotein (HDL) (mg/dL), creatinine (mg/dL), serum nitrogen (mg/ $\mathrm{dL}$ ), serum uric acid (SUA) (mg/dL), fibrinogen $(\mathrm{mg} / \mathrm{dL})$, calcium $(\mathrm{mg} / \mathrm{dL})$, phosphorus $(\mathrm{mg} / \mathrm{dL})$, serum electrolytes (mEq/L), C-reactive protein (CRP) $(\mu \mathrm{g} / \mathrm{L})$, homocysteine (Hcy) ( $\mu \mathrm{mol} / \mathrm{L})$, hemoglobin $(\mathrm{Hb})(\mathrm{g} /$ $\mathrm{dL}$ ), were measured using standard automated techniques. The total white blood cell count (WBC) and the neutrophil, lymphocyte and platelet counts were recorded. The neutrophil-lymphocyte ratio (NLR), was calculated by dividing the absolute neutrophil count by the absolute lymphocyte count $(\mathrm{NLR}<2.8$, was defined as low in our study). LDL-cholesterol was calculated using the Friedewald equation: LDL (mg/dL) $=$ total cholesterol-HDL- (triglycerides/5). Parathyroid Hormone was measured using a two-site assay that measures "intact" hormone (iPTH) (pg/mL) and 25-hydroxyvitaminD (25-OH-VitD) (ng/mL) was measured by radioimmunoassay. Cardiac troponin $\mathrm{T}(\mathrm{cTnT})(\mathrm{ng} / \mathrm{mL})$ were measured using automated analyzer Elecsys ®2010 (Roche Elecsys 2010 chemistry analyzer, Cobas Integra 400 Plus Analyzer, Geislingen, Germany). Serum albumin $(\mathrm{g} / \mathrm{dL}$ ) was determined by bromcresol purple method. Insulin resistance was assessed using the homeostasis model assessment (HOMA-IR), originally described by Mathew et al [20]. Microalbuminuria $24 \mathrm{~h}$ (30-300 mg/24h) were carried out.

\section{Anthropometric assessments}

Body weight was determined to the nearest $0.1 \mathrm{~kg}$ using a calibrated digital scale. Body mass index was calculated from a person's weight and height [weight $\left.(\mathrm{kg}) / \mathrm{height}^{2}\left(\mathrm{~m}^{2}\right)\right]$.

\section{Blood pressure measurements}

Blood pressure (BP) measurements were made in the dominant arm, after 10 minutes of rest in the sitting position, using a standard automatic sphygmomanometer and cuffs adapted to the arm circumference [21]. The mean of the three measurements was recorded for statistical analyses.

The systolic and diastolic BP levels were taken as the points of appearance and disappearance of Korotkoff sounds, respectively. Hypertension was defined as systolic BP $\geq 140 \mathrm{mmHg}$ or diastolic $\mathrm{BP} \geq 90$ $\mathrm{mmHg}$ on repeated measurements. We have determined Ankle Brachial Index (ABI), the measurement of the ratio of the systolic blood pressures in the ankle and in the arm (normal values 0.9-1) [22].

Echocardiography

All patients underwent transthoracic echocardiography with a commercially available cardiovascular
Table 1. Patient' s characteristics. Data are show as
mean \pm standard deviation. Abbreviations: SBP, diurnal systolic blood pressure; DBP, diurnal diastolic blood pressure; ADPKD, autosomal dominant polycystic

\begin{tabular}{lccc}
\hline & $\begin{array}{c}\text { ADPKD } \\
(\mathrm{n}: 26)\end{array}$ & $\begin{array}{c}\text { Control Group } \\
(\mathrm{n}: 24)\end{array}$ & p value \\
\hline SBP (mmHg) & $122.6 \pm 15.2$ & $120.8 \pm 9.9$ & n.s. \\
DBP (mmHg) & $78.2 \pm 9.7$ & $73.1 \pm 10.8$ & n.s. \\
duration of hypertension (yrs) & $8.2 \pm 4.1$ & $6.7 \pm 3.3$ & n.s. \\
Ace inhibitors (num) & 8 & 6 & n.s. \\
ARBs (num) & 4 & 3 & n.s. \\
Ca-antagonists (num) & 7 & 8 & n.s. \\
$\beta$-blockers (num) & 2 & 1 & n.s. \\
\hline
\end{tabular}




\section{Kidney Blood Pressure Research}

Lai et al.: Cardiovascular Risk in ADPKD

ultrasound system (Vivid E9, GE, Horten, Norway). Measurements of cardiac chambers were made according to established criteria [23-24]. LV ejection fraction by modified biplane Simpson method and mass index were estimated. Peak early (E) and late (A) diastolic velocities, deceleration time, left ventricular isovolumic relaxation time, and myocardial performance index were obtained using standard Doppler practices. Standard parasternal, apical, and subcostal views were used.

Common carotid intima-media thickness assessment (IMT)

Right (R) and left (L) carotid ultrasound was blindly performed by an experienced sonographer, who was unaware of the characteristics of the patients under examination. Participants were studied with the high-resolution B-mode ultrasound machine Toshiba Aplio XV (Toshiba AplioxV, Toshiba American Medical Systems, Inc., Tustin, CA, USA) equipped with a 5- to 12-MHz linear transducer with a 0.01-mm resolution, following a standardized vascular protocol [25]. IMT was measured at three points on the far walls of both left and right distal common carotid arteries, carotid bulb, and the proximal portion of the internal carotid arteries. The mean IMT was calculated as the average IMT on both sides. The value of IMT was considered normal when between 0.55 and $0,9 \mathrm{~mm}$ [26].

\section{Flow-mediated dilation brachial artery (FMD)}

According to the method described by Celermajer and others [27], the endothelium-dependent vasodilation (FMD) of the brachial artery was assessed using a high-resolution B-mode ultrasound machine Toshiba Aplio XV (Toshiba AplioxV, Toshiba American Medical Systems, Inc., Tustin, CA, USA), equipped with a 5- to $12 \mathrm{MHz}$ linear transducer with a 0.01-mm resolution, by the same blinded experienced ultrasonographer, following a standardized vascular protocol [28]. Flow-mediated vasodilatation was typically expressed as the change in post-stimulus diameter as a percentage of the baseline diameter. FMD: (diameter post-hyperemia-basal diameter/basal diameter) x 100. The values of FMD were considered normal if they were greater than $10 \%$.

\section{Renal Resistive index (RRI)}

Participants were studied with the high-resolution B-mode ultrasound machine Toshiba Aplio XV (Toshiba AplioxV, Toshiba American Medical Systems, Inc., Tustin, CA, USA) equipped with a 3-3.5 MHz convex transducer. All measurements were made by a single, blinded, experienced ultrasonographer. Renal resistive index (RRI) values were determined with the mean of three separate measurements in the renal superior pole, interpolar regional and inferior pole on the level of the interlobular, interlobar or arcuate arteries in both kidneys. We used an anterior and an oblique approach, to detect the renal arteries and intraparenchymal vessels, and we used a posterior approach with adjustment of direction if the cystic lesions were too large and did not permit a clear view. Three to five reproducible and consecutive waveforms with similar aspect from each kidney were obtained. These measurements were used to calculate the average RI value for each kidney, and then the average RI value for each patient was calculated as the mean of the RI in the left and right kidney [29]. We determined the peak systolic velocity and end-diastolic velocity (centimeters/second) to calculate the RRI as = [1-(end-diastolic velocity $\div$ maximal systolic velocity) $] \times 100$ [30-31]. The intra-reader correlation coefficient for RRI was 0.97, whereas the inter-reader was 0.92 .

\section{Magnetic Resonance Imaging (MRI)}

All patients underwent MR examinations at 3T magnet to assess the presence of intracranial arterial aneurysms and Total kidney volume. Imaging was performed with a 3.0-T MR unit (Verio; Siemens, Erlangen, Germany).

\section{Respiratory function testing (Spirometry)}

Spirometries were executed with the subjects in sitting position, wearing a nose clip according to the international guidelines [32-33]. Before testing each subject, the spirometer was calibrated using a certified 3-L syringe. A laboratory spirometer and Quark spirometry software (Quark PFT Suite Version 9.1a, COSMED, Pavona, Italy) were used to measure forced expiratory volume in one second $\left(\mathrm{FEV}_{1}\right)$ and forced vital capacity (FVC). 


\section{Kidney Blood Pressure Research}

Lai et al.: Cardiovascular Risk in ADPKD

\section{Cardiopulmonary exercise testing (CPET)}

All subjects performed an incremental exercise test up to peak work capacity on an electronically braked cycle ergometer (COSMED, Pavona, Italy), using the Quark b² system (Version 8.1a, COSMED, Pavona, Italy) according to guidelines [34]. All participants were continuously monitored by means of a 12-lead electrocardiograph. Blood pressure was measured every minute using a sphygmomanometer. Percentage of arterial oxygen saturation was continuously measured using a pulse oximeter. Oxygen uptake $\left(\mathrm{V}^{\prime} \mathrm{O}_{2}\right)$, carbon dioxide production $\left(\mathrm{V}^{\prime} \mathrm{CO}_{2}\right)$ and minute ventilation $\left(\mathrm{V}^{\prime} \mathrm{E}\right)$ were detected. CPET consisted of a steady-state resting period, then one minute of warm-up without load, followed by a stepwise protocol in which the work rate was increased in 1-minute intervals by increments of 10 Watt.The exercise test was considered maximal for a value of respiratory exchange ratio (RER) $>1.05$. The test was continued until the point of symptom limitation (peak exercise). Subjects were asked to score their sense of breathlessness and muscle fatigue throughout the exercise and at peak exercise using Borg scale [35]. The Lactic Threshold (LT) was detected individually using the V-slope method [36]. Workload (W), LT, maximal oxygen consumption $\left(\mathrm{V}^{\prime} \mathrm{O}_{2 \max }\right)$ and HR peak values, BP for each subject were compared with those obtained in a group of healthy subjects matched for age, height, weight and gender.

\section{Statistical analysis}

Data management and analysis were performed using IBM $₫$ SPSS $®$ Statistics 18.0 for Windows $®$ software (IBM Corporation, New Orchard Road Armonk, New York, United States). The normality of variables was tested using the Shapiro-Wilk method for normal distributions. All continuous variables were expressed as mean \pm standard deviation, categorical variables were expressed as number (percentage). The comparison of the data of patients, for all quantitative variables considered was performed using non-parametric Wilcoxon test and Student's t test. For comparing proportions was applied Chi-Square Test. Student's t-test or-Mann-Whitney U-test were performed to determine differences between groups. Binomial Test or Chi-square test was used for

Table 2. Patient's characteristics. Data are shown as mean \pm standard deviation. Abbrevitions: BMI, Body Mass Index; SBP, Systolic Blood Pressure; DBP, Diastolic Blood Pressure; eGFR, estimated Glomerular Filtration Rate; Hb, Hemoglobin; NLR, Neutrophil / Lymphocyte ratio; HDL, highdensity lipoprotein; LDL, low-density lipoprotein; iPTH, intact Parathormone; 25-OH-VitD, 25-hydroxyvitaminD; Hcy, homocysteine; cTnT, Cardiac troponin T; CRP, C-reactive protein

\begin{tabular}{|c|c|c|c|}
\hline Variable & ADPKD & Control Group & $\mathrm{p}$ value \\
\hline Age & $31.7 \pm 9.1$ & $27.8 \pm 4.5$ & 0.067 \\
\hline BMI & $22.9 \pm 2.8$ & $22.6 \pm 2.0$ & 0.665 \\
\hline SBP (mmHg) & $122.6 \pm 15.2$ & $120.8 \pm 9.9$ & 0.632 \\
\hline $\mathrm{DBP}(\mathrm{mmHg})$ & $78.2 \pm 9.7$ & $73.1 \pm 10.8$ & 0.090 \\
\hline eGFR $(\mathrm{mL} / \mathrm{min})$ & $98.9 \pm 19.9$ & $107.2 \pm 9.1$ & 0.066 \\
\hline Creatinine $(\mathrm{mg} / \mathrm{dL})$ & $0,81 \pm 0,15$ & $0.77 \pm 0.13$ & 0.320 \\
\hline hATKV $\mathrm{cm} 3$ & $820.06 \pm 812.82$ & & \\
\hline Urea (mg/dL) & $37.6 \pm 10.1$ & $33.4 \pm 5.0$ & 0.075 \\
\hline Uric Acid (mg/dL) & $5.1 \pm 1.1$ & $3.542 \pm 0.116$ & $<0.001$ \\
\hline Sodium $(\mathrm{mEq} / \mathrm{L})$ & $140.4 \pm 1.8$ & $140.2 \pm 2.3$ & 0.654 \\
\hline Potassium (mEq/L) & $4.3 \pm 0.3$ & $4.1 \pm 0.3$ & 0.073 \\
\hline Clalcium (mEq/L) & $9.4 \pm 0.4$ & $9.2 \pm 0.2$ & 0.068 \\
\hline Posphorus (mEq/L) & $3.5 \pm 0.5$ & $3.3 \pm 0.5$ & 0.114 \\
\hline $\mathrm{Hb}(\mathrm{g} / \mathrm{dL})$ & $13.2 \pm 1.4$ & $13.0 \pm 1.2$ & 0.665 \\
\hline Neutrofil $\left(x 10^{3} / \mathrm{mL}\right)$ & $3990.7 \pm 1305.1$ & $4445.8 \pm 1497.4$ & 0.257 \\
\hline Lymphocyte $\left(10^{3} / \mathrm{mL}\right)$ & $1569.4 \pm 701.6$ & $2520.2 \pm 516.0$ & $<0.001$ \\
\hline NLR & $2.72 \pm 1.42$ & $1.76 \pm 0.55$ & 0.003 \\
\hline HOMA-IR & $2.51 \pm 1.50$ & $1.35 \pm 0.47$ & $<0.001$ \\
\hline Glycemia (mg/dL) & $86.4 \pm 8.2$ & $83.5 \pm 7.6$ & 0.201 \\
\hline Total Colesterol $(\mathrm{mg} / \mathrm{dL})$ & $176.3 \pm 32.2$ & $156.3 \pm 28.5$ & 0.025 \\
\hline $\mathrm{HDL}(\mathrm{mg} / \mathrm{dL})$ & $59.2 \pm 16.9$ & $64.9 \pm 14.4$ & 0.212 \\
\hline $\mathrm{LDL}(\mathrm{mg} / \mathrm{dL})$ & $98.8 \pm 8.2$ & $76.0 \pm 9.4$ & $<0.001$ \\
\hline Tryglicerides (mg/dL) & $85.7 \pm 34.0$ & $73.3 \pm 28.2$ & 0.170 \\
\hline iPTH $(\mathrm{pg} / \mathrm{mL})$ & $48.4 \pm 23.2$ & $35.9 \pm 10.6$ & 0.019 \\
\hline$(25-\mathrm{OH}-\mathrm{VitD})(\mathrm{ng} / \mathrm{mL})$ & $14.0 \pm 9.5$ & $28.3 \pm 6.2$ & $<0.001$ \\
\hline Fibrinogen $(\mathrm{mg} / \mathrm{dL})$ & $312.0 \pm 79.4$ & $267.9 \pm 44.6$ & 0.020 \\
\hline Albumin $(\mathrm{g} / \mathrm{dL})$ & $4.343 \pm 0.377$ & $4.805 \pm 0.435$ & 0.002 \\
\hline $\mathrm{Hcy}(\mu \mathrm{mol} / \mathrm{L})$ & $16.628 \pm 7.724$ & $8.917 \pm 1.984$ & $<0.001$ \\
\hline CTnT(ng/mL) & $0.014 \pm 0.019$ & $0.003 \pm 0.004$ & 0.007 \\
\hline $\mathrm{CRP}(\mu \mathrm{g} / \mathrm{L})$ & $7007.6 \pm 6950.1$ & $1206.8 \pm 1122.1$ & 0.002 \\
\hline
\end{tabular}

\section{Results}

The study included 26 consecutive patients affected by ADPKD (6 male; 20 female), with a mean age of $31.7 \pm 9.1$ years, and 24 control group (8 male; 16 female), with a mean age of $27.8 \pm 4.5$ years. Population characteristics are shown in Table 2 . There were no significant differences between the two groups regarding age, BMI, BP, eGFR $(\mathrm{ml} / \mathrm{min})$, sodium (mEq/L), potassium $(\mathrm{mEq} / \mathrm{L})$, calcium $(\mathrm{mg} / \mathrm{dL})$, phosphorus $(\mathrm{mg} / \mathrm{dL})$, glycemia $(\mathrm{mg} / \mathrm{dL})$, serum nitrogen $(\mathrm{mg} /$ $\mathrm{dL})$, and $\mathrm{Hb}(\mathrm{g} / \mathrm{dL})$, while we reported a significant difference in SUA $(\mathrm{mg} / \mathrm{dL})$, Hcy $(\mu \mathrm{mol} / \mathrm{L})$ and HOMA-IR, $(\mathrm{p}<0.001$, $\mathrm{p}<0.001, \mathrm{p}<0.001$; respectively) (Table 2). Moreover, we found higher iPTH $(\mathrm{pg} / \mathrm{mL})$ in 


\section{Kidney Blood Pressure Research}

ADPKD patients (mg/dL) respect to control group, although within normal values, $(p=0.019)$ (Table 2) and lower 25-OH-VitD (ng/mL) $(\mathrm{p}<0.001)$ (Table 2). Inflammatory indexes, as NLR, CRP ( $\mu \mathrm{g} / \mathrm{L})$ and fibrinogen, were significantly higher in ADPKD patients respect to control group $(\mathrm{p}=0.003$, $\mathrm{p}=0.002, \mathrm{p}=0.020$; respectively) (Table 2). Total Cholesterol (mg/ $\mathrm{dL})$ and LDL $(\mathrm{mg} / \mathrm{dL})$ were significantly different between the two groups $(\mathrm{p}=0.025, \mathrm{p}<0.001$; respectively), while HDL (mg/ $\mathrm{dL})$ and triglycerides (mg/dL) did not show significant differences ( $\mathrm{p}=0.212, \mathrm{p}=0.170$; respectively) (Table 2). Also albumin (g/ $\mathrm{dL}$ ) value, was significantly different between the two groups, although within normal values $(p=0.002)$. Furthermore, we found significantly higher mean values of LVMI $\left(\mathrm{g} / \mathrm{m}^{2}\right)$, RRI and cTnT (ng/ $\mathrm{mL})(\mathrm{p}<0.001, \mathrm{p}<0.001, \mathrm{p}=0.007$; respectively), and lower FMD value $(\mathrm{p}<0.001)$ (Table 2 , Table 3$)$, in ADPKD patients versus control group, while we did not found a significant difference in IMT and ABI values $(p=0.932, p=0.495$; respectively), between the two groups (Table 3). In ADPKD patients, the study correlation showed a positive correlation between HOMA-IR and CRP

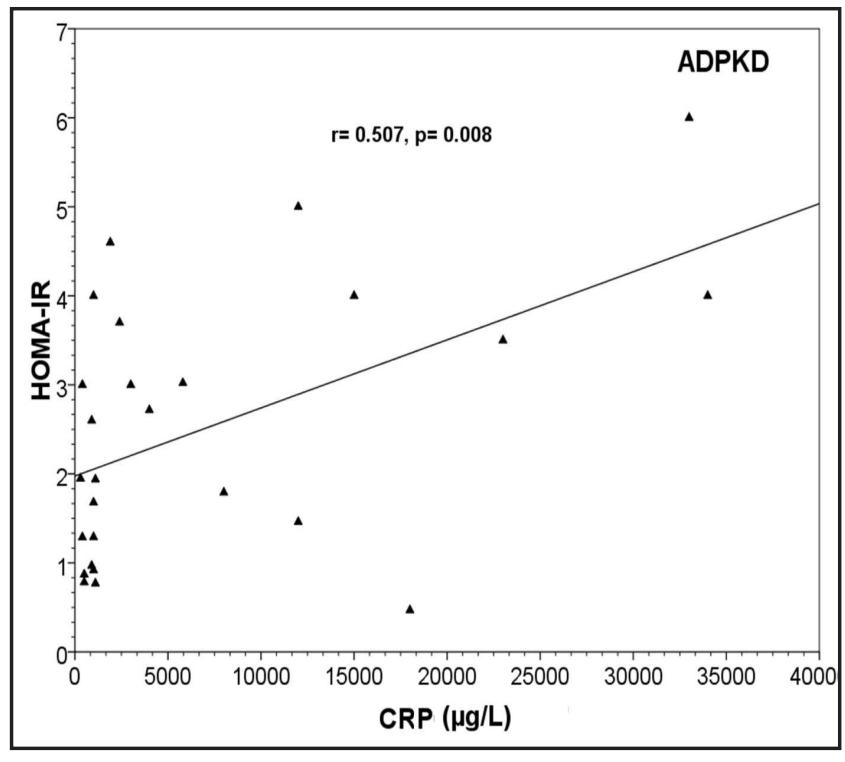

Fig. 1. Linear regression plot. Correlation between HOMAIR and CRP $(\mu \mathrm{g} / \mathrm{L})$ in ADPKD patients, $r=0.507, \mathrm{p}=0.008$. Abbreviations: HOMA-IR, homeostasis model assessment of insulin resistance; ADPKD, autosomal dominant polycystic kidney disease; $\mathrm{CRP}, \mathrm{C}$ reactive protein.

Table 3. Instrumental parameters of the study participants. Data are shown as mean \pm standard deviation. Abbreviations: ADPKD autosomal dominant polycystic kidney disease; FMD, flow mediated dilation; cIMT, carotid intima media thickness; LVMI, left ventricular mass index; RRI, renal resistive index; $\mathrm{ABI}$, ankle brachial index

\begin{tabular}{lccc}
\hline Variable & ADPKD & Control Group & $\mathrm{p}$ value \\
\hline FMD & $11,23 \pm 5,66$ & $27,46 \pm 5,29$ & $<0,001$ \\
cIMT & $0,65 \pm 0,13$ & $0,64 \pm 0,12$ & 0.779 \\
LVMI & $125,04 \pm 24,12$ & $83,80 \pm 11,43$ & $<0,001$ \\
RRI & $0,64 \pm 0,057$ & $0,55 \pm 0,03$ & $<0,001$ \\
ABI & $1.01 \pm 0.06$ & $1.00 \pm 0.04$ & 0.495 \\
\hline
\end{tabular}
$(\mathrm{r}=0.507, \mathrm{p}=0.008)$ (Fig. 1), and a negative correlation between HOMA-IR and 25-OH-VitD $(\mathrm{r}=-0.585, \mathrm{p}=0.002)$ (Fig. 2). Also, we found significantly reduced parameters of exercise tolerance, as $V^{\prime} \mathrm{O}_{2 \max }, V^{\prime} \mathrm{O}_{2 \max } / \mathrm{Kg}$ and $V^{\prime} \mathrm{O}_{2 \max }(\%$ predicted $)(\mathrm{p}<0.001, \mathrm{p}<0.001, \mathrm{p}=0.018$; respectively) and metabolic response indexes $\left(V^{\prime} \mathrm{O}_{2} @ \mathrm{LT}, V^{\prime} \mathrm{O}_{2} @ \mathrm{LT} \%, V^{\prime} \mathrm{O}_{2} @ \mathrm{LT} / \mathrm{Kg},\right)(\mathrm{p}<0.001$, $\mathrm{p}=0.14, \mathrm{p}<0.001$; respectively) in ADPKD patients compared to control group (Table 4). Conversely, we found significantly increased the ventilatory equivalent for $\mathrm{CO}_{2}, V^{\prime} \mathrm{E} / V^{\prime} \mathrm{CO}_{2} @$ LT $(p<0.001)$. HR peak was reduced in ADPKD patients $(\mathrm{p}<0.001)$, while no statistically significant difference was found in HR rest $(p=0.351)$. The remaining parameters of the CPET did not show statistically significant differences between the two groups.

\section{Discussion}

The most important finding of our study is the early appearance of inflammatory indexes, endothelial dysfunction, atherosclerotic and metabolic markers associated with a reduction of parameters of exercise tolerance and metabolic response indexes in ADPKD patients 


\section{Kidney Blood Pressure Research}

respect to control group. ADPKD is characterized by several cardiovascular complications, which represent the main cause of death of this disease [11]. The onset of cardiac manifestations, such as hypertension, left ventricular hypertrophy (LVH), cardiac valvular abnormalities and pericardial effusions, may precede the development of renal failure [9]. Despite the pathogenetic mechanisms are not well understood, endothelial dysfunction, inflammation, and insulin resistance, are the most commonly encountered risk factors in the pathogenesis of cardiovascular disease in ADPKD patients, also in the early stages of disease [37]. Leier etal.[11] hypothesized a generalized connective tissue dysfunction, with a deficiency or absence of type III collagen. Several lines of evidence, suggest a hyperactivation of reninangiotensin-aldosterone system (RAAS), with ectopic production of renin, angiotensinogen, angiotensin-converting enzyme and angiotensin II by cystic epithelium [2, 12]. Angiotensin II seems to represent the main stimulus for the production of aldosterone, and the presence of hyperaldosteronism in ADPKD, could contribute to the development of insulin resistance and endothelial dysfunction, with impaired nitric oxide-related vasorelaxation, and progression of cardiorenal disease [15]. Recently, some authors showed an essential role of the cilia in proper development of the vascular system [16]. Insufficient expression of PC1 or PC2 could be associated with functional or structural abnormalities of the vascular system, determining a reduced release of nitric oxide with altered endothelial response to shear stress and reduced vasodilation [17]. Our data confirm that ADPKD patients, with preserved renal function, show a significant higher LVMI (Table 3), which is likely multifactorial, and may be influenced by vitamin D deficiency, hyperparathyroidism and insulin resistance [38]. In this study, we showed higher mean value of iPTH, although remaining within the normal range, and lower 25-OH-VitD levels in ADPKD

Fig. 2. Linear regression plot. Correlation between HOMA-IR and 25-OH-VitD (ng/mL) in ADPKD patients, $r=-0.585, \mathrm{p}=0.002$. Abbreviations: HOMA-IR, homeostasis model assessment of insulin resistance; ADPKD, autosomal dominant polycystic kidney disease;

Table 4. Instrumental parameters of the study participants. Data are shown as mean \pm standard deviation. Abbreviations: ADPKD, autosomal dominant polycystic kidney disease; $\mathrm{V}^{\prime} \mathrm{O}_{2 \max }$ maximum oxygen uptake; $V^{\prime} O_{2 \max }(\%$ predicted), maximum oxygen uptake percent of predicted; $\mathrm{V}^{\prime} \mathrm{O}_{2 \max } / \mathrm{Kg}$, maximum oxygen uptake ratio for kilogram; V'O @LT, oxygen uptake at lactic threshold; V'O $\mathrm{O}_{2} @ \mathrm{LT}$ (\% predicted) oxygen uptake at lactic threshold percent of predicted; $\mathrm{V}^{\prime} \mathrm{O}_{2} @ \mathrm{LT} / \mathrm{Kg}$ ventilatory heart rate

\begin{tabular}{lccc}
\hline Variable & ADPKD & Control Group & p value \\
\hline $\mathrm{V}^{\prime} \mathrm{O}_{2 \max }(\mathrm{ml} / \mathrm{min})$ & $1646,00 \pm 395,69$ & $2430,20 \pm 503,08$ & $<0,001$ \\
$\mathrm{~V}^{\prime} \mathrm{O}_{2 \max }(\% \mathrm{predicted})$ & $79,74 \pm 13,82$ & $90,09 \pm 16,21$ & 0,018 \\
$\mathrm{~V}^{\prime} \mathrm{O}_{2 \max } / \mathrm{Kg}(\mathrm{ml} / \mathrm{min} / \mathrm{Kg})$ & $25,04 \pm 3,36$ & $33,62 \pm 5,03$ & $<0,001$ \\
$\mathrm{~V}^{\prime} \mathrm{O}_{2} @ \mathrm{LT}(\mathrm{ml} / \mathrm{min})$ & $906,67 \pm 163,95$ & $1299,79 \pm 415,46$ & $<0,001$ \\
$\mathrm{~V}^{\prime} \mathrm{O}_{2} @ \mathrm{LT}(\% \mathrm{predicted})$ & $40,42 \pm 8,58$ & $47,68 \pm 11,52$ & 0,014 \\
$\mathrm{~V}^{\prime} \mathrm{O}_{2} @ \mathrm{LT} / \mathrm{Kg}(\mathrm{ml} / \mathrm{min} / \mathrm{Kg})$ & $13,07 \pm 3,36$ & $17,87 \pm 4,68$ & $<0,001$ \\
$\mathrm{~V}^{\prime} \mathrm{E} / \mathrm{V} \mathrm{CO}_{2} @ \mathrm{LT}$ & $28,24 \pm 2,94$ & $24,61 \pm 3,37$ & $<0,001$ \\
$\mathrm{HR}$ rest $(\mathrm{bpm})$ & $80,36 \pm 15,34$ & $84,04 \pm 11,86$ & 0,350 \\
$\mathrm{HR}$ peak $(\mathrm{bpm})$ & $155,04 \pm 18,95$ & $172,79 \pm 11,13$ & $<0,001$ \\
\hline
\end{tabular}




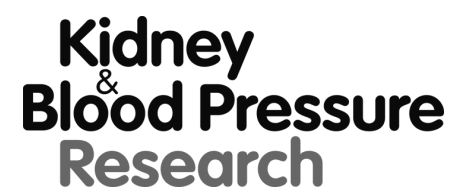

\begin{tabular}{l}
\hline Kidney Blood Press Res 2017;42:1290-1302 \\
\begin{tabular}{l|l} 
DOI: 10.1159/000486011 & C 2017 The Author(s). Published by S. Karger AG, Basel \\
Published onlIne: December 15, 2017 & www.karger.com/kbr
\end{tabular} \\
\hline
\end{tabular}

Lai et al.: Cardiovascular Risk in ADPKD

patients, compared to control group. Although the involvement of Vitamin D in ADPKD is not fully elucidated, it is known that it is responsible of pleiotropic effects, by binding to the vitamin D receptor (VDRs), in non-classical targets, including cardiovascular, immuneendocrine, and nervous systems [26]. Moreover, Vitamin D deficiency reduces intestinal calcium absorption by more than $50 \%$, and determines an increase in the levels of iPTH. An increased iPTH level may be associated with left ventricular and vascular medial smooth muscle hypertrophy. Vitamin D deficiency, and/or increased iPTH, could, at least partially, explain hypertrophy of the left ventricle and proliferation of vascular smooth muscle cells, promoting atherosclerosis and endothelial dysfunction [39-40]. Vitamin D is also involved in glycemic control, insulin secretion, and sensitivity, partially explaining the negative correlation found in our study, between 25-OH-VitD and HOMA-IR (Fig. 2). Currently, the link between polycystin function and insulin resistance, in ADPKD patients with preserved renal function, is still poorly known [41], even if recently Mao et al. [42] showed that polycystin proteins could regulate insulin secretion, being expressed in pancreatic islet beta cells. Other significant metabolic alterations were observed in ADPKD patients in our study, like higher Hcy and SUA respect to control group. Both of them are independent risk factors for atherosclerosis and cardiovascular disease [26], and could influence the endothelial dysfunction, through the generation of oxidative stress, promoting the development of inflammation and atherosclerosis [43]. Moreover in ADPKD patients, SUA may be considered an independent factor for renal progression [44], and associated with earlier onset of larger kidney volume, hypertension, and increased hazard for ESRD [45-46]. Chronic inflammation has been shown to be an independent predictor of cardiovascular mortality in ADPKD patients [47]. In our study, inflammatory markers as CRP, fibrinogen levels and NLR were significantly higher in patients with ADPKD compared to control group, in the early stages of disease. Moreover, CRP showed a positive correlation with HOMA-IR (Fig. 1). In recent years, NLR was introduced as a potential marker to determine inflammation in cardiac and noncardiac diseases [48]. The early metabolic and inflammatory changes that we showed, could explain the lower FMD value, and the higher mean values of LVMI and RRI, which are early markers of endothelial and cardiac dysfunction, in ADPKD patients respect to control group [49-51]. Conversely, in our study, we have not revealed a significant difference in IMT and ABI, indexes of subclinical atherosclerosis, perhaps because ADPKD patients are still in the early stages of disease. Indeed, endothelial dysfunction is an early and potentially reversible manifestation of atherosclerosis, with multifactorial etiology [52-54], and it develops in ADPKD patients, preceding the renal failure [55-56]. Atherosclerosis has been considered to play a key role in the early phases of cardiovascular disease found in ADPKD [57-59]. Cardiopulmonary exercise testing is considered the gold-standard for assessment of cardiorespiratory fitness. Measurement of maximum oxygen uptake $\left(\mathrm{V}^{\prime} \mathrm{O}_{2 \text { max }}\right)$ is the most important parameter used in the evaluation of exercise tolerance. Cardiopulmonary exercise testing measures the integrated physiological responses to exercise of respiratory, cardiovascular, and skeletal muscle systems [60]. In our study, we found a statistically significant reduction of parameters of exercise tolerance as $V^{\prime} \mathrm{O}_{2 \max } \mathrm{V}^{\prime} \mathrm{O}_{2 \max } / \mathrm{Kg}$ and $V^{\prime} \mathrm{O}_{2 \max }(\%$ predicted), and metabolic response indexes $\left(V^{\prime} \mathrm{O}_{2} @ L T, V^{\prime} \mathrm{O}_{2} @ L T \%, V^{\prime} \mathrm{O}_{2} @ L T / \mathrm{Kg}\right.$,) (Table 4), in ADPKD patients compared to control group. The ventilatory equivalent for $\mathrm{CO} 2$ at lactate threshold $\left(V^{\prime} \mathrm{E} / V^{\prime} \mathrm{CO}_{2} @ \mathrm{LT}\right)$ was significantly increased in ADPKD patients (Table 4). Impaired physical capacity in young patients with ADPKD could be explained by underlying endothelial dysfunction, which could depend on inadequate response of nitric oxide, asymmetric dimethylarginine, and BP to acute exercise [36, 61]. Several studies have identified $V^{\prime} E / V^{\prime} C O_{2}$, anaerobic threshold, and $V^{\prime} O_{2 \max }$ as prognostic factors in cardiovascular diseases [62-63]. We found, also, a significant increase of cTnT in ADPKD patients, a sensitive and specific marker of ischemic myocardial damage, renally cleared, and widely used as a predictor of cardiovascular events [53]. Our results indicate an increase of the indexes of inflammation and endothelial dysfunction, with reduced tolerance to stress and decreased anaerobic threshold to CPET, in young ADPKD patients, with preserved renal function, in the early stages of disease, compared to control 


\section{Kidney Blood Pressure Research}

group. Moreover CPET could allow an early assessment of maximum oxygen uptake and anaerobic threshold, and it could be used in the follow up to assess response to possible therapeutic strategies, as vitamin D supplement, hyperuricemia and hyperhomocysteinemia correction, diet and regular physical activity, that could improve the exercise tolerance and metabolic state [64].

\section{Limitation of the study}

This study was conducted in relatively small cohort of ADPKD patients; therefore should be considered as hypothesis generating data, which need to be confirmed by further clinical studies with a larger number of patients. Moreover, it is based on associations with surrogate end points, indeed it demonstrated an 'association', rather than a 'causality' relationship; the generated hypothesis thus needs further prospective follow-up studies with a larger number of patients and stronger end points to show causality.

\section{Conclusion}

Cardiovascular manifestations are common in ADPKD, and starts very early during the course of the disease. There are currently no prognostic tools to identify ADPKD patients with high cardiovascular risk [65]. The early and noninvasive evaluation of inflammatory indexes, endothelial dysfunction, atherosclerotic markers and HOMA-IR, in addiction to mineral metabolism indexes and cTnT may be necessary to improve the cardiovascular prognosis of affected patients, especially in the early stages of disease, when renal function is still preserved, despite the cost implication. Large clinical trials are needed to establish cardiovascular risk in ADPKD patients and further studies are necessary to determine if the progression of ADPKD is modified by treatment risk factors, such as vitamin D deficit, insulin resistance, hyperuricemia and hyperhomocysteinemia [66].

\section{Disclosure Statement}

The authors report no conflicts of interest. The authors alone are responsible for the content and writing of the paper. The manuscript has been seen and approved by all authors. The manuscript is not under consideration for publication elsewhere.

\section{References}

$>1$ Loghman-Adham M, Soto CE, Inagami T, Cassis L: The intrarenal renin-angiotensin system in autosomal dominant polycystic kidney disease. Am J Physiol Renal Physiol 2004;287:F775-788.

2 Trujillano D, Bullich G, Ossowski S, Ballarín J, Torra R, Estivill X, Ars E: Diagnosis of autosomal dominant polycystic kidney disease using efficient PKD1 and PKD2 targeted next-generation sequencing. Mol Genet Genomic Med 2014;2:412-421.

3 Iglesias CG, Torres VE, Offord KP, Holley KE, Beard CM, Kurland LT: Epidemiology of adult polycystic kidney disease, Olmsted County, Minnesota: 1935-1980. Am J Kidney Dis 1983;2:630-639.

-4 Spithoven EM, Kramer A, Meijer E, Orskov B, Wanner C, Abad JM, Aresté N, de la Torre RA, Caskey F, Couchoud C, Finne P, Heaf J, Hoitsma A, de Meester J, Pascual J, Postorino M, Ravani P, Zurriaga O, Jager KJ, Gansevoort RT, et al.: Renal replacement therapy for autosomal dominant polycystic kidney disease (ADPKD) in Europe: prevalence and survival--an analysis of data from the ERA-EDTA Registry. Nephrol Dial Transplant 2014;29:iv15-25.

5 Torres VE1, Harris PC: Polycystic kidney disease in 2011:connecting the dots toward a polycystic kidney disease therapy. Nat Rev Nephrol 2011;8:66-86. 


\section{Kidney \\ Blood Pressure Research}

6 The European Polycystic Kidney Disease Consortium: The polycystic kidney disease 1 gene encodes a $14 \mathrm{~kb}$ transcript and lies within a duplicated region on chromosome 16. Cell 1994;78:725.

7 Mochizuki T, Wu G, Hayashi T, Xenophontos SL, Veldhuisen B, Saris JJ, Reynolds DM, Cai Y, Gabow PA, Pierides A, Kimberling WJ, Breuning MH, Deltas CC, Peters DJ, Somlo S: PKD2, a gene for polycystic kidney disease that encodes an integral membrane protein. Science 1996;272:1339-1428.

-8 Watnick T, Germino GG: Molecular basis of autosomal dominant polycystic kidney disease. Semin Nephrol 1999;19:327-343.

-9 Luciano RL, Dahl NK: Extra-renal manifestations of autosomal dominant polycystic kidney disease (ADPKD): considerations for routine screening and management. Nephrol Dial Transplant 2014;29:247254.

10 Ecder T: Cardiovascular complications in autosomal dominant polycystic kidney disease. Curr Hypertens Rev 2013;9:2-11.

11 Leier CV, Baker PB, Kilman JW, Wooley CF: Cardiovascular abnormalities associated with adult polycystic kidney disease. Ann Intern Med 1984;100:683-688.

12 Wanic-Kossowska M, Posnik B, Kobelski M, Pawliczak E, Pawlaczyk K, Hoppe K, Schwermer K, Sikorska D: The polymorphism of the ACE gene affects left ventricular hypertrophy and causes disturbances in left ventricular systolic/diastolic function in patients with autosomal dominant polycystic kidney disease. Sci World J 2014;2014:707658.

-13 Torres VE, Donovan KA, Scicli G, Holley KE, Thibodeau SN, Carretero OA, Inagami T, McAteer JA, Johnson CM: Synthesis of renin by tubulocystic epithelium in autosomal-dominant polycystic kidney disease. Kidney Int 1992;42:364-373.

14 Gnanasambandan R, Elumalai R, Soundararajan P, Lakkakula BV: Angiotensinogen gene polymorphisms and progression of chronic kidney disease in ADPKD patients. Clin Exp Nephrol 2016;20:561-568.

-15 Lai S, Petramala L, Mastroluca D, Petraglia E, Di Gaeta A, Indino E, Panebianco V, Ciccariello M, Shahabadi HH, Galani A, Letizia C, D’Angelo AR: Hyperaldosteronism and cardiovascular risk in patients with autosomal dominant polycystic kidney disease. Medicine (Baltimore) 2016;95:e4175.

16 Kallakuri S, Yu JA, Li J, Li Y, Weinstein BM, Nicoli S, Sun Z: Endothelial cilia are essential for developmental vascular integrity in zebrafish. J Am Soc Nephrol 2015;26:864-875.

-17 Di Lorenzo A, Stallone G, Infante B, Grandaliano G, Schena FP: Cardiovascular risk in polycystic kidney disease. G Ital Cardiol 2015;16:479-484.

18 Pei Y, Obaji J, Dupuis A, Paterson AD, Magistroni R, Dicks E, Parfrey P, Cramer B, Coto E, Torra R, San Millan JL, Gibson R, Breuning M, Peters D, Ravine D: Unified criteria for ultrasonographic diagnosis of ADPKD. J Am Soc Nephrol 2009;20:205-212.

19 Inker LA, Levey AS: Pro: Estimating GFR using the chronic kidney disease epidemiology collaboration (CKD-EPI) 2009 creatinine equation: the time for change is now. Nephrol Dial Transplant 2013;28:13901396.

20 Matthews DR, Hosker JP, Rudenski AS, Naylor BA, Treacher DF, Turner RC: Homeostasis model assessment: Insulin resistance and beta-cell function from fasting plasma glucose and insulin concentrations in man. Diabetologia 1985;28:412-419.

-21 Williams B, Poulter NR, Brown MJ, Davis M, McInnes GT, Potter JF, Sever PS, Thom SM: BHS guidelines working party, for the British Hypertension Society. British Hypertension Society guidelines for hypertension management 2004 (BHS-IV): summary. BMJ 2004;328:634-640.

-22 Price JF, Tzoulaki I, Lee AJ, Fowkes FG: Ankle brachial index and intima media thickness predict cardiovascular events similarly and increased prediction when combined. J Clin Epidemiol 2007;60:10671075.

23 Lang RM, Bierig M, Devereux RB, Flachskampf FA, Foster E, Pellikka PA, Picard MH, Roman MJ, Seward J, Shanewise JS, Solomon SD, Spencer KT, Sutton MS, Stewart WJ, Chamber Quantification Writing Group, American Society of Echocardiography's Guidelines and Standards Committee, European Association of Echocardiography: Recommendations for chamber quantification: a report from the American Society of Echocardiography's Guidelines and Standards Committee and the Chamber Quantification Writing Group, developed in conjunction with the European Association of Echocardiography, a branch of the European Society of Cardiology. J Am Soc Echocardiogr 2005;18:1440-1463. 


\section{Kidney \\ Blood Pressure Research}

24 Schiller NB, Shah PM, Crawford M, DeMaria A, Devereux R, Feigenbaum H, Gutgesell H, Reichek N, Sahn D, Schnittger I: Recommendations for quantitation of the left ventricle by two-dimensional echocardiography. American Society of Echocardiography Committee on Standards, Subcommittee on Quantitation of TwoDimensional Echocardiograms. J Am Soc Echocardiogr 1989;2:358-367.

25 Lai S, Coppola B, Dimko M, Galani A, Innico G, Frassetti N, Mariotti A: Vitamin D deficiency, insulin resistance, and ventricular hypertrophy in the early stages of chronic kidney disease. Ren Fail 2014;36:5864. Ho CY, Solomon SD: A clinician's guide to tissue Doppler imaging. Circulation 2006;113:396-398.

Patel S, Celermajer DS: Assessment of vascular disease using arterial flow mediated dilatation. Pharmacol Rep 2006;58:3-7.

28 Corretti MC, Anderson TJ, Benjamin EJ: Guidelines for the ultrasound assessment of endothelial-dependent flow mediated vasodilation of the brachial artery: A report of the International Brachial Artery Reactivity Task Force. J Am Coll Cardiol 2002;39:257-265.

29 Ramunni A, Saracino A, Esposito T, Saliani MT, Coratelli P: Renal vascular resistance and renin-angiotensin system in the pathogenesis of early hypertension in autosomal dominant polycystic kidney disease. Hypertens Res 2004;27:221-225.

-30 Radermacher J, Chavan A, Bleck J, Vitzthum A, Stoess B, Gebel MJ, Galanski M, Koch KM, Haller H: Use of Doppler ultrasonography to predict the outcome of therapy for renal artery stenosis. N Engl J Med 2001;344:410-417.

-31 Cianci R, Martina P, Cianci M, Lavini R, Stivali G, Di Donato D, Polidori L, Lai S, Renzulli R, Gigante A, Barbano B: Ischemic nephropathy: proteinuria and renal resistance index could suggest if revascularization is recommended. Ren Fail 2010;32:1167-1171.

-32 Miller MR, Hankinson J, Brusasco V, Burgos F, Casaburi R, Coates A, Crapo R, Enright P, van der Grinten CP, Gustafsson P, Jensen R, Johnson DC, MacIntyre N, McKay R, Navajas D, Pedersen OF, Pellegrino R, Viegi G, Wanger J: ATS/ERS Task Force: Standardisation of spirometry. Eur Respir J 2005;26:319-338.

33 Pellegrino R, Viegi G, Brusasco V, Crapo RO, Burgos F, Casaburi R, Coates A, van der Grinten CP, Gustafsson P, Hankinson J, Jensen R, Johnson DC, MacIntyre N, McKay R, Miller MR, Navajas D, Pedersen OF, Wanger J: Interpretative strategies for lung function tests. Eur Respir J 2005;26:948-968.

-34 American Thoracic Society; American College of Chest Physicians: ATS/ACCPstatement on cardiopulmonary exercise testing. Am J Respir Crit Care Med 2003;167:211-277.

-35 Borg GA: Psychophysical basis of perceived exertion. Med Sci Sports Exerc 1982;14:377-381.

-36 Wasserman K: The anaerobic threshold measurement to evaluate exerciseperformance. Am Rev Respir Dis 1984;129:S35-40.

-37 Martinez-Vea A, Bardaj A, Gutierrez C, Garca C, Peralta C, Marcas L, Oliver JA: Exercise blood pressure, cardiac structure, and diastolic function in young normotensive patients with polycystic kidney disease: a prehypertensive state. Am J Kidney Dis 2004;44:216-223.

-38 Lumiaho A, Pihlajamäki J, Hartikainen J, Ikäheimo R, Miettinen R, Niemitukia L, Lampainen E, Laakso M: Insulin resistance is related to left ventricular hypertrophy in patients with polycystic kidney disease type 1. Am J Kidney Dis 2003;41:1219-1224.

39 Lai S, Coppola B, Dimko M, Galani A, Innico G, Frassetti N, Mariotti A: Vitamin D deficiency, insulin resistance, and ventricular hypertrophy in the early stages ofchronic kidney disease. Ren Fail 2014;36:5864.

40 Mekahli D, Bacchetta J: From bone abnormalities to mineral metabolism dysregulation in autosomal dominant polycystic kidney disease. Pediatr Nephrol 2013;28:2089-2096.

41 Vareesangthip K, Tong P, Wilkinson R, Thomas TH: Insulin resistance in adult polycystic kidney disease. Kidney Int 1997;52:503-508.

42 Mao Z, Xie G, Ong AC: Metabolic abnormalities in autosomal dominant polycystic kidney disease. Nephrol Dial Transplant 2015;30:197-203.

43 Klawitter J, Reed-Gitomer BY, McFann K, Pennington A, Klawitter J, Abebe KZ, Klepacki J, Cadnapaphornchai MA, Brosnahan G, Chonchol M, Christians U, Schrier RW: Endothelial dysfunction and oxidative stress in polycystic kidney disease. Am J Physiol Renal Physiol 2014;307:F1198-1206. 


\section{Kidney \\ Blood Pressure Research}

Lai et al.: Cardiovascular Risk in ADPKD

-44 Han M, Park HC, Kim H, Jo HA, Huh H, Jang JY, Kang AY, Kim SH, Cheong HI, Kang DH, Yang J, Oh KH, Hwang YH, Ahn C: Hyperuricemia and deterioration of renal function in autosomal dominant polycystic kidney disease. BMC Nephrol 2014;15:63.

45 Helal I, McFann K, Reed B, Yan XD, Schrier RW, Fick-Brosnahan GM: Serum uric acid, kidney volume and progression in autosomal-dominant polycystic kidney disease. Nephrol Dial Transplant 2013;28:380-385.

-46 Kocyigit I, Yilmaz MI, Orscelik O, Sipahioglu MH, Unal A, Eroglu E, Kalay N, Tokgoz B, Axelsson J, Oymak O: Serum uric acid levels and endothelial dysfunction in patients with autosomal dominant polycystic kidney disease. Nephron Clin Pract 2013;123:157-164.

-47 Núñez J, Núñez E, Bodí V, Sanchis J, Miñana G, Mainar L, Santas E, Merlos P, Rumiz E, Darmofal H, Heatta $\mathrm{AM}$, Llàcer A: Usefulness of the neutrophil to lymphocyte ratio in predicting long-term mortality in ST segment elevation myocardial infarction. Am J Cardiol 2008;101:747-752.

48 Tang L, Li X, Wang B, Luo G, Gu L, Chen L, Liu K, Gao Y, Zhang X: Prognostic Value of Neutrophil-toLymphocyte Ratio in Localized and Advanced Prostate Cancer: A Systematic Review and Meta-Analysis. PLoS One 2016;11:e0153981.

49 Turkmen K, Tufan F, Selçuk E, Akpınar T, Oflaz H, Ecder T: Neutrophil-to-lymphocyte ratio, insulin resistance, and endothelial dysfunction in patients with autosomal dominant polycystic kidney disease. Indian J Nephrol 2013;23:34-40.

50 Nowak KL, Farmer H, Cadnapaphornchai MA, Gitomer B, Chonchol M: Vascular dysfunction in children and young adults with autosomal dominant polycystic kidney disease. Nephrol Dial Transplant 2017;32:342347.

51 Chapman AB, Johnson A, Gabow PA, Schrier RW: The renin-angiotensin-aldosterone system and autosomal dominant polycystic kidney disease. N Engl J Med 1990;323:1091-1096.

-52 Ramunni A, Saracino A, Esposito T, Saliani MT, Coratelli P: Renal vascular resistance and renin-angiotensin system in the pathogenesis of early hypertension in autosomal dominant polycystic kidney disease. Hypertens Res 2004;27:221-225.

-53 Lai S, Dimko M, Galani A, Coppola B, Innico G, Frassetti N, Mazzei ED, Mariotti A: Early markers of cardiovascular risk in chronic kidney disease. Ren Fail 2015;37:254-261.

54 Calabia J, Torguet P, Garcia I, Martin N, Mate G, Marin A, Molina C, Valles M: The relationship between renal resistive index, arterial stiffness, and atherosclerotic burden: the link between macrocirculation and microcirculation. J Clin Hypertens 2014;16:186-191.

55 Lin YH, Lin LY, Chen A, Wu XM, Lee JK, Su TC, Wu VC, Chueh SC, Lin WC, Lo MT, Wang PC, Ho YL, Wu KD, Group TS: Adrenalectomy improves increased carotid intima-media thickness and arterial stiffness in patients with aldosterone producing adenoma. Atherosclerosis 2012;221:154-159.

56 Hokimoto S, Soejima H, Kojima S, Kaikita K, Yamamuro M, Izumiya Y, Tsujita K, Yamamoto E, Tanaka T, Sugamura K, Arima Y, Sakamoto K, Akasaka T, Tabata N, Sueta D, Miyoshi I, Usami M, Ogawa H: Distribution of Ankle-Brachial Index among Inpatients with Cardiovascular Disease: Analysis Using the Kumamoto University Hospital Medical Database. Ann Vasc Dis 2016;9:229.

57 Tokiwa S, Muto S, China T, Horie S: The relationship between renal volume and renal function in autosomal dominant polycystic kidney disease. Clin Exp Nephrol 2011:539-545.

-58 Sag S, Yildiz A, Gullulu S, Gungoren F, Ozdemir B, Cegilli E, Oruc A, Ersoy A, Gullulu M: Early atherosclerosis in normotensive patients with autosomal dominant polycystic kidney disease: the relation between epicardial adipose tissue thickness and carotid intima-media thickness. Springerplus 2016;5:211.

-59 Peterson KM, Franchi F, Loeffler DL, Psaltis PJ, Harris PC, Lerman LO, Lerman A, Rodriguez-Porcel M: Endothelial dysfunction occurs prior to clinical evidence of polycystic kidney disease. Am J Nephrol 2013;38:233-240.

-60 Palange P, Ward SA, Carlsen K-H, Casaburi R, Gallagher CG, Gosselinke R, O’Donnell DE, Puente-Maestu L, Schols AM, Singh S, Whipp BJ: Recommendations on the use of exercise testing in clinical practice. Eur Respir J 2007;29:185-209.

-61 Wensel R, Opitz CF, Anker SD, Winkler J, Höffken G, Kleber FX, Sharma R, Hummel M, Hetzer R, Ewert R: Assessment of survival in patients with primary pulmonary hypertension: importance of cardiopulmonary exercise testing. Circulation 2002;106:319-324. 


\section{Kidney Research}

-62 Gitt AK, Wasserman K, Kilkowski C, Kleemann T, Kilkowski A, Bangert M, Schneider S, Schwarz A, Senges J: Exercise anaerobic threshold and ventilatory efficiency identify heart failure patients for high risk of early death. Circulation 2002;106:3079-3084.

63 Reinecke NL, Cunha TM, Heilberg IP, Higa EM, Nishiura JL, Neder JA, Almeida WS, Schor N: Exercise capacity in polycystic kidney disease. Am J Kidney Dis 2014;64:239-246.

64 Bolignano D, Palmer SC, Ruospo M, Zoccali C, Craig JC, Strippoli GF: Interventions for preventing the progression of autosomal dominant polycystic kidney disease. Cochrane Database Syst Rev 2015;7:CD010294.

65 Kapoor S, Rodriguez D, Mitchell K, Wüthrich RP: High Resolution Ultrasonography for Assessment of Renal Cysts in the PCK Rat Model of Autosomal Recessive Polycystic Kidney Disease. Kidney Blood Press Res 2016;41:186-196.

66 Rodriguez D, Kapoor S, Edenhofer I, Segerer S, Riwanto M, Kipar A, Yang M, Mei C, Wüthrich RP: Inhibition of Sodium-Glucose Cotransporter 2 with Dapagliflozin in Han: SPRD Rats with Polycystic Kidney Disease. Kidney Blood Press Res 2015;40:638-647. 